\title{
Modelo INSERTE de mediación escolar para el desarrollo de competencias sociocognitivas, emocionales y morales
}

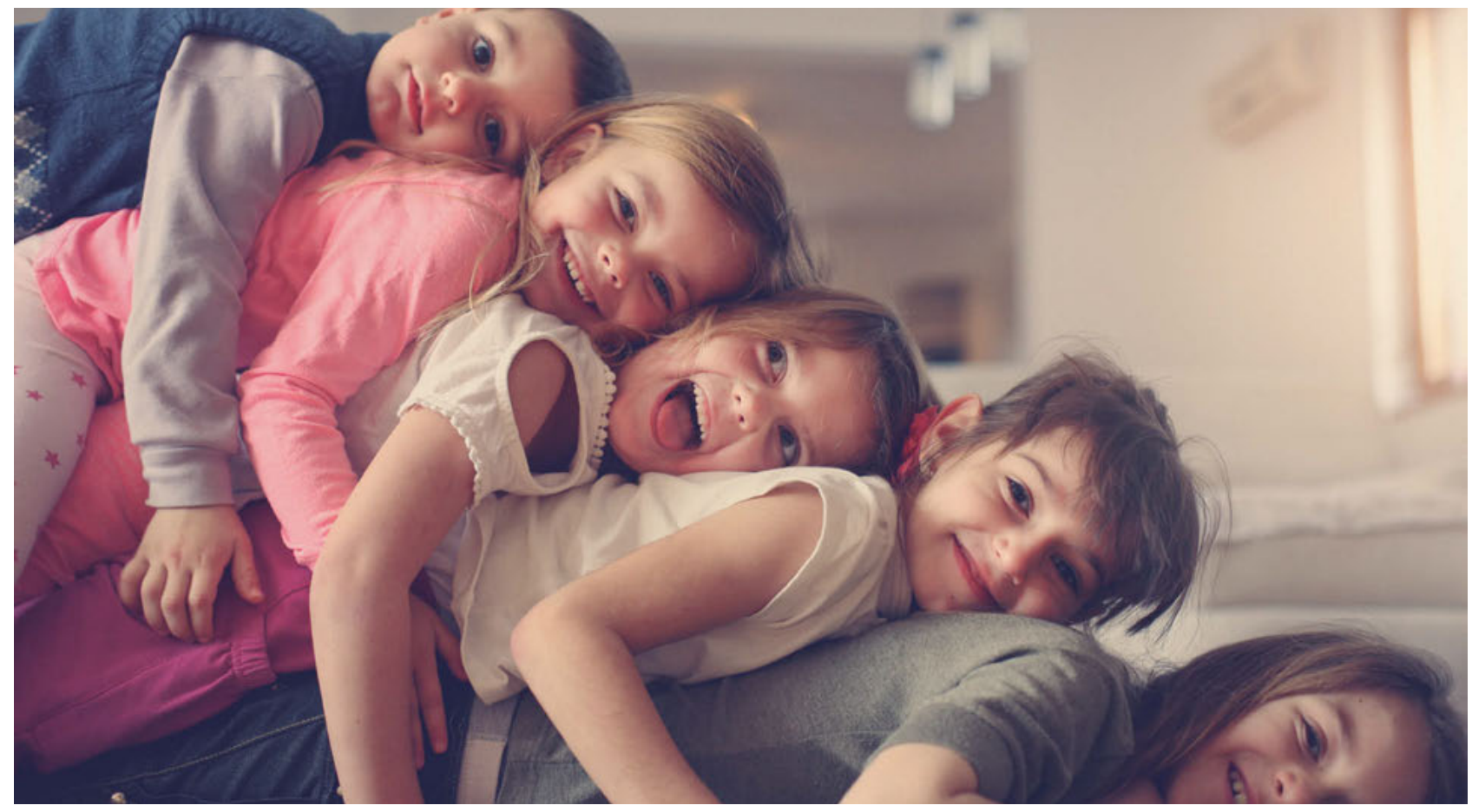

La mediación escolar es altamente beneficiosa en los centros escolares. Sigue creciendo el número de mediadores escolares, alumnos ayudantes y cibermentores en nuestro país. El programa e-AMEDIAR de Padre Piquer de

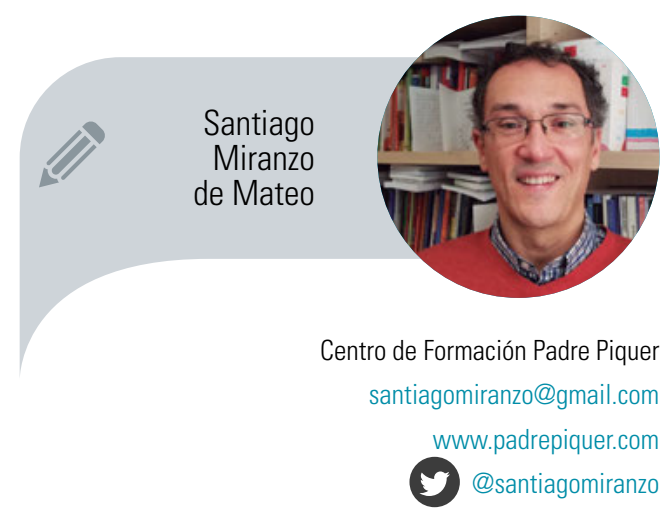
Madrid, basado en el modelo INSERTE de mediación escolar y prevención del acoso escolar, ha formado desde 2005 a más de 100 mediadores y 500 facilitadores de resolución inteligente de conflictos (RIC). 


\section{La mediación escolar tiene sus principios}

La mediación escolar lleva más de 30 años aplicándose en España, más de 10.000 mediadores escolares, alumnos ayudantes y cibermentores formados por España... y creciendo. La comunidad internacional de mediadores escolares nace en pequeños proyectos como los que os mostraré en este especial de mediación escolar, en centros públicos y en centros concertados, en distintas comunidades autónomas de España y en otros países europeos, todos suman esfuerzos para luchar contra la violencia.

El programa e-AMEDIAR de Padre Piquer de Madrid basado en el modelo INSERTE de mediación escolar y prevención del acoso escolar, que ha formado desde 2005 a más de 100 mediadores y 500 facilitadores de RIC (resolución inteligente de conflictos) atrae a búhos, delfines y camaleones para que conformen el Observatorio de la Convivencia que los alumnos mediadores despliegan para lograr que reine un clima pacífico y de sana convivencia entre los 1.200 alumnos de más de 37 nacionalidades que conviven en Padre Piquer. Este programa de mediación escolar forma parte del SIFA (Servicio de intervención a familias y alumnos) creado en el año 2000 mediante un convenio de colaboración entre el centro educativo Padre Piquer y la UNINPSI (Unidad de Intervención Psicosocial) de la Universidad Pontificia Comillas. En el SIFA se ofrece asesoramiento terapéutico y mediación, así es como lo hacemos y como puedes llegar a hacerlo.

La filosofía de la mediación es la de crear un espacio distinto de encuentro, en el que las partes protagonistas puedan gestionar el conflicto de una manera más efectiva a como lo hacen fuera de la mediación.

La mediación es una metodología que organiza el futuro a partir de los recursos del presente teniendo en cuenta el aprendizaje del pasado. A los adolescentes se lo explico en la formación diciendo que es como el agua, que refresca y te da energía, te acoge y acepta con todo lo que tú

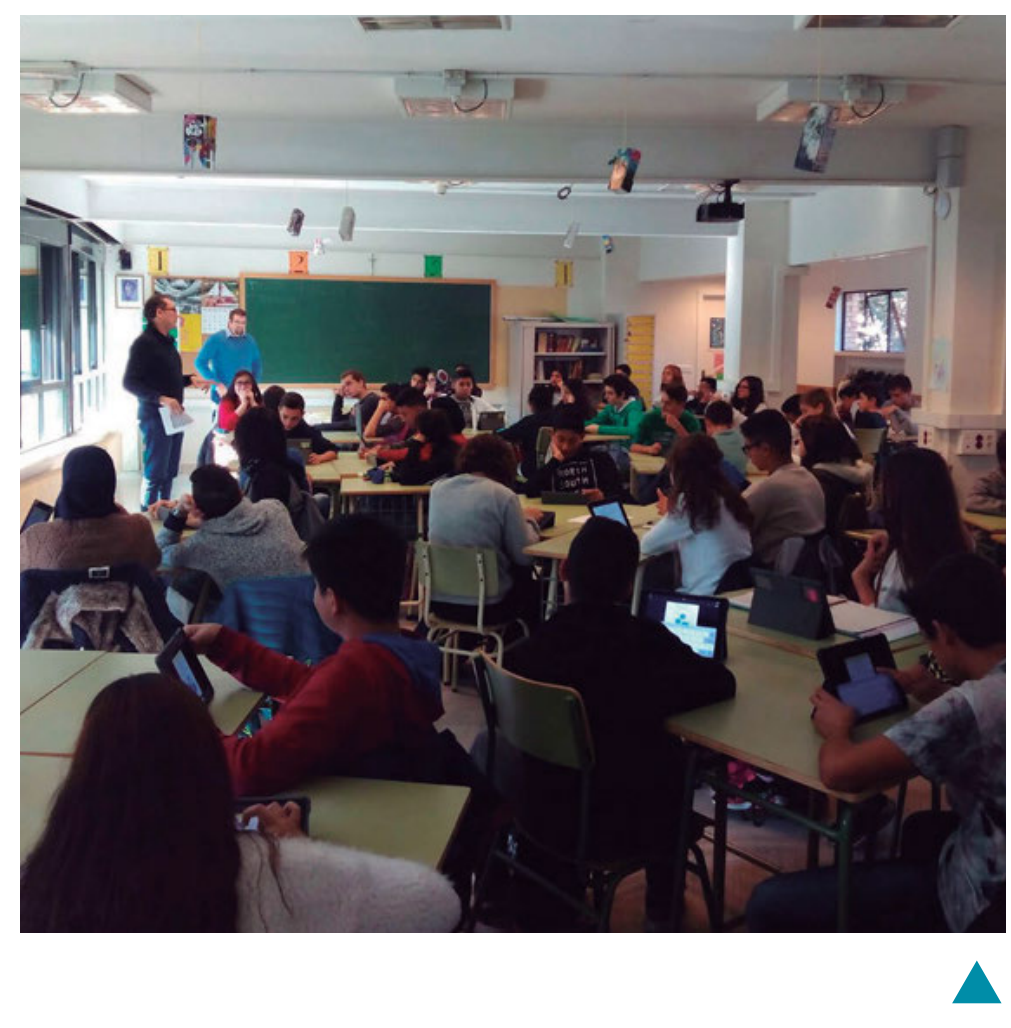

eres (tu pasado), te hace consciente de todas las sensaciones y energías que atesoras (tu presente) y, cuando te sientes demasiado "sediento" para seguir avanzando, te empodera y lanza hacia adelante, hacia el logro de tus metas (futuro).

La mediación se centra en el futuro, quiere organizar la relación a partir de ahora, sabe que se puede soñar y crear el futuro, acordar lo que haremos a partir de ahora, cambiar. Parte del presente, de los recursos de los protagonistas, de hacerles ver que "en la mochila de la vida", si rebuscan, encontrarán todo lo necesario para reponer fuerzas y afrontar el resto de etapas del camino, de empoderarles para que refuercen su autoestima y autoconocimiento y, si necesitan reforzar o añadir alguna competencia aún no desarrollada, los ayudas a reflexionar cómo conseguirlas. Y reflexiona sobre el pasado en la medida en la que sirve para organizar el futuro, partiendo de que el pasado no se puede cambiar y al que solo hay que dedicar el tiempo mínimo necesario para que se pueda organizar el futuro, es decir, en los momentos en los que hay que arropar las emociones desbordadas que el acontecimiento generó en los protagonistas y que, de no ser reconocidas, impiden el avance del proceso.

El inicio de la mediación educativa en España se establece a partir de los años 90, a través de profesores que habían es- mediadores escolares, en un aula cooperativa con IPAD, de $3^{\circ}$ ESO del centro escolar Padre

Piquer de Madrid 


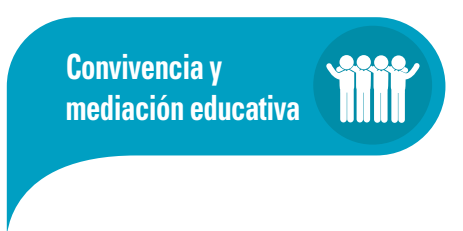

\section{La implantación de programas de mediación educativa en los centros favorece el desarrollo de competencias sociocognitivas, emocionales y morales por lo que es un instrumento idóneo para resolver necesidades escolares}

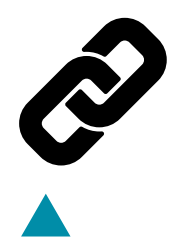

Programa SALT de Madrid en 1998. tado en otros países en los que se habían aplicado estos programas o experiencias educativas, como Estados Unidos, donde se aplicaban desde finales de los 60. El País Vasco en 1993 y Cataluña en 1996 fueron las comunidades autónomas pioneras en su implementación. En Madrid fue Torrego el primero que realizó un programa piloto en diez institutos de la Comunidad

Algunas de las experiencias más exitosas y reconocidas de mediación escolar son las de Juan Carlos Torrego en la Comunidad de Madrid (creador del modelo integrado), Ramón Alzate en el País Vasco (creador del modelo global), Eduard Vinyamata y Carme Boqué en Cataluña (creadora del modelo en red), Rosario Ortega en Andalucía, Fermín Romero en Canarias, etc.

Existen actualmente un gran número de IES y colegios que aplican programas de mediación educativa en España en todas las etapas educativas. Sánchez García-Arista recopila unos 60 en su libro y explica cómo en el País Vasco fue el Centro de Investigación por La Paz Guernika Gogoratuz el que inicia la mediación educativa y ahora continúa su labor con el equipo universitario desde GEUZ. De esta comunidad autónoma recogemos en uno de los artículos de este número de Padres y Maestros la interesante experiencia del Programa KIDE de prevención del acoso escolar y facilitación del aprendizaje.

En Madrid hemos de destacar la experiencia desarrollada por Torrego en la década de los 90 del siglo pasado implementando el modelo integrado, un programa de mediación educativa en 24 institutos de la Comunidad de Madrid, formando a profesores y a alumnos como mediadores a partir del modelo integrado de mediación educativa, así como la investigación de resultados que ha realizado al respecto. En este número traemos la interesante experiencia del IES San Juan Bautista, en el que la orientadora del centro escolar $\mathrm{M}^{\mathrm{a}}$. José Gómez Puig Ileva implementando el programa de alumnos ayudantes a través del modelo integrado apostando, entre otras medidas, por la creación de estructuras que den protagonismo al alumnado, fomentando la ayuda entre iguales, así como al programa e-AMEDIAR.

A nivel europeo la mediación educativa está ampliamente extendida. Por falta de espacio físico no he podido incluir en este número de la revista dos experiencias interesantísimas que se están desarrollando en Irlanda y en Portugal. Las resumo someramente y dejo el enlace al texto para quien quiera profundizar.

En Irlanda e Inglaterra, Fiona McAuslan ha creado un programa innovador para los alumnos de educación primaria llamado en inglés SALT = Stop, Ask, Listen, Talk (en español sería SPEH stop, preguntar, escuchar, hablar) en el que los chicos aprenden qué es el conflicto, cómo te sientes al tener un conflicto y cómo negociar eficazmente para crear una solución aceptable para todos. El programa se focaliza en favorecer la capacidad de cada niño para desarrollar y manejar su propio kit de habilidades ante el afrontamiento de situaciones difíciles y emotivas (para más información pueden contactar con ella a través del email: f.mcauslan@ gmail.com).

En Portugal, la mediación como método de intervención social en el contexto educativo, surge en la década de los 90 y los proyectos de mediación de conflictos escolares (PMCE) se iniciaron en el año 2000. La profesora Elisabette Pinto da Costa, de la Universidade Lusófona do Porto, sostiene que los PMCE generan procesos de mejora de la escuela en términos educativos, sociales y organizacionales, en favor de su calidad educativa y de su función socializadora. La metodolo- 


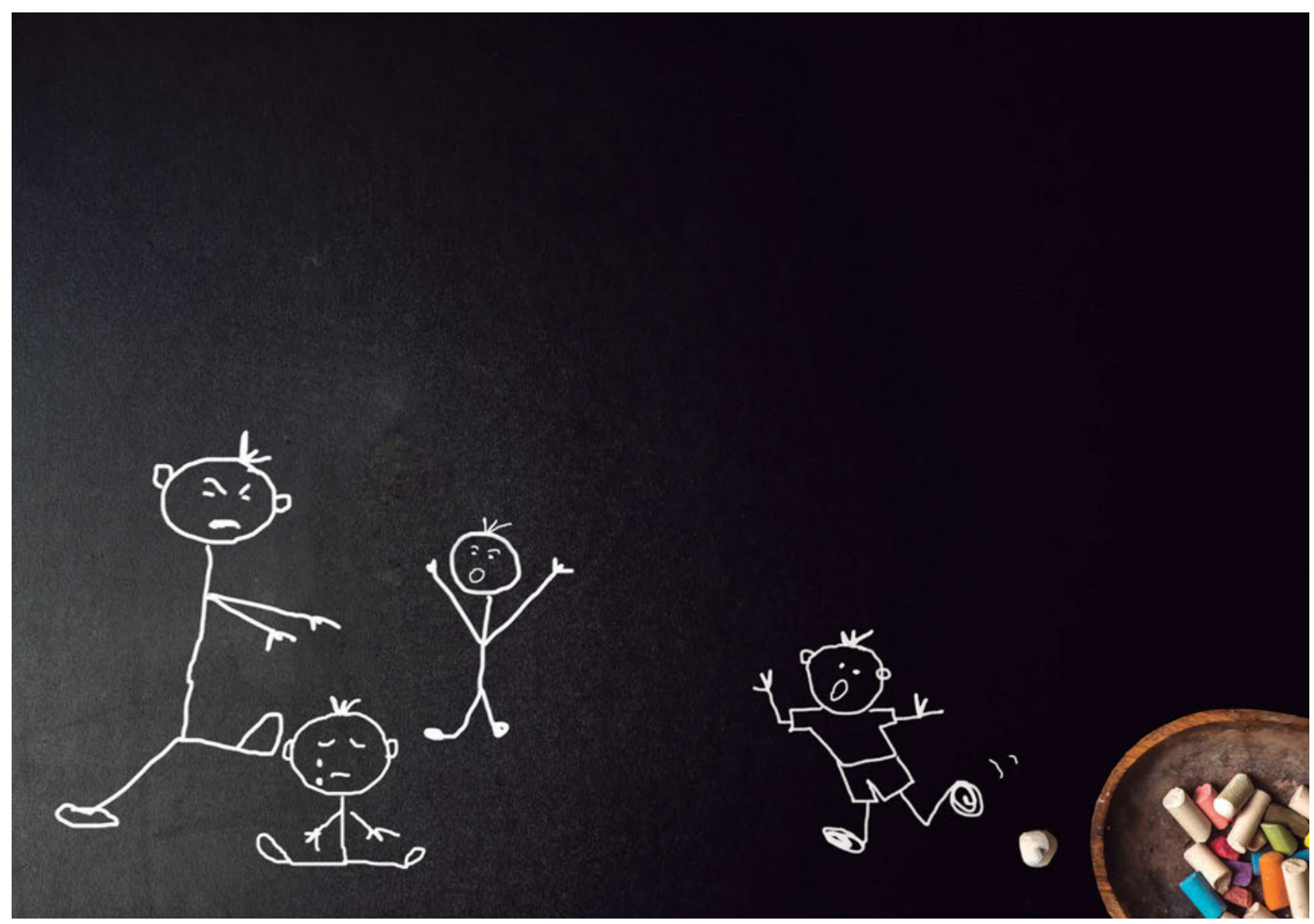

gía PMCE propone una intervención amplia y sostenible que requiere como condición sine qua non que se involucre toda la comunidad educativa. La escuela es una entidad aprendedora, capaz de innovar y, así, acompañar y apoyar a la innovación propuesta a los sujetos que la constituyen, en una coherencia expresiva de valores, creencias, principios y normas. Además de los individuos, denominador común de este tipo de intervención, interesa la escuela, detentora de una cultura propia. Todos esos elementos forman parte de las dimensiones de un proyecto PMCE, la procesual, la interpersonal/social y la organizacional. Estas tres dimensiones deben ser cuidadas de forma articulada, como si existiera un flujo de sinergias mutuas (para más información pueden contactar con ella a través del email: elisabete.pinto.costa@ulp.pt).

A nivel internacional, siguiendo a una de las autoras de este especial de mediación educativa, Sánchez García-Arista, los orígenes de los programas de mediación educativa son los programas de mediación comunitaria expandidos por todo EE. UU. en la década de los setenta del siglo $X X$, tras el éxito de los primeros Centros de Justicia Vecinal que impulsó el presidente Jimmy Carter. De aquí se extendió al resto de continentes. Durante la década de los ochenta, se traslada esta experiencia a los centros escolares de EE. UU. para favorecer que los alumnos resuelvan los conflictos utilizando técnicas para mediar. Los cuatro primeros programas de resolución de conflictos y mediación educativa en Estados Unidos eran el Teaching Students to be Peacemakers Program, el Children's Creative Response to Conflict Program, el Resolving Conflict Creatively Program y los President Carter's Neighborhood Justice Centers.

Con respecto a la evolución de la mediación educativa como medio de resolución de conflictos, debe nombrarse el auge que ha tenido desde el año 2006 los programas de prevención del acoso escolar (bullying en inglés). Ya se venían realizando programas de este tipo, pero ha sido la difusión a nivel internacional de los éxitos del programa KIVA de Finlandia, la que ha hecho aumentar considerablemente este tipo de programas, especialmente centrados en el ciberacoso (ciberbullying en inglés). En 


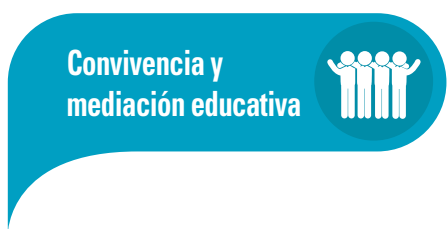

Objetivos del programa e-AMEDIAR del modelo INSERTE de mediación educativa

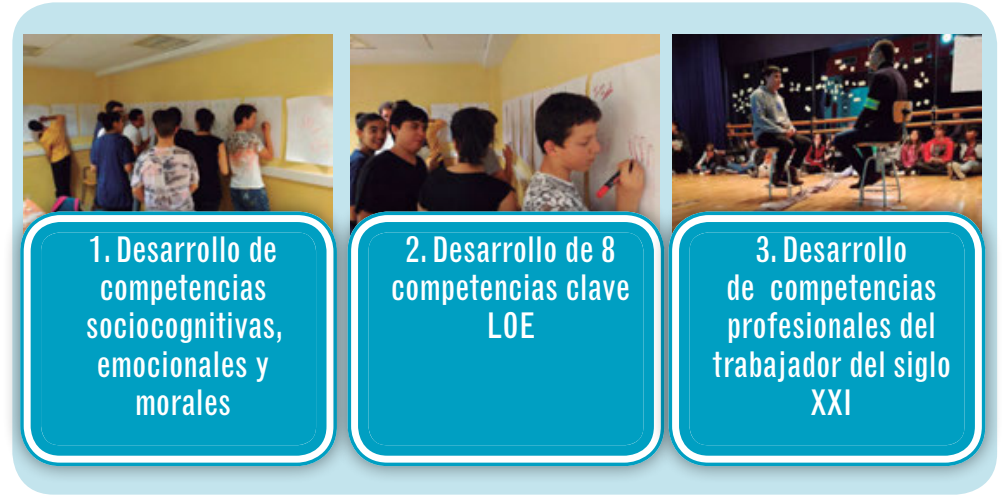

España ya hay asociaciones como Lookschool que han creado protocolos para la prevención e intervención en casos de hostigamiento (bullying) y que han creado un modelo de certificación para centros educativos (No Bullying Pro). Por eso en este número especial incorporamos la propuesta de la asociación Lookschool para que los padres conozcamos qué es el bullying y sepamos cómo podemos ayudar a prevenirlo. En la parte práctica se aporta además la herramienta: ¡Todos a una! Contra el acoso escolar que se ha puesto en marcha en centros educativos a través de la asociación Jupsin.

\section{La mediación escolar es mediación educativa}

Si bien en otros ámbitos, como en la mediación para la separación y el divorcio, la mediación es utilizada desde una concepción más instrumentalizada y centrada en el conflicto y su solución, la mediación educativa tiene un claro potencial educativo. Optar por esta concepción, como indica la mediadora Carme Boqué, supone partir de los valores de la mediación para propiciar el cambio social hacia una coexistencia no violenta de todas las personas.

Coincido con Ibarrola en destacar las virtualidades educativas de la mediación al afirmar que, desde una perspectiva educativa el objetivo de la mediación no puede ser solo erradicar la existencia de conflictos, sino que la mediación para ser educativa debe ir más allá y ampliar su foco de actuación. La ausencia de conflictos en el centro escolar no aseguraría una buena convivencia ni un correcto desarrollo personal de los alumnos, razón por la que la mediación para ser educativa debe plantearse con el deseo de lograr el desarrollo socioafectivo en todas las personas que entran en contacto con ella, así como de lograr efectos a largo plazo en la cultura de centro.

He creado el programa e-AMEDIAR partiendo de una definición de mediación educativa centrada en el desarrollo de competencias. Mi interés reside en demostrar que la implantación de programas de mediación educativa en los centros escolares favorece el desarrollo de competencias sociocognitivas, emocionales y morales y que es un instrumento idóneo para resolver necesidades escolares.

Para lograrlo realicé una investigación sobre mediación educativa y desarrollo de 29 competencias sociocognitivas, emocionales y morales por los alumnos tras formarse como mediadores escolares con el programa e-AMEDIAR como criterio medidor de los beneficios que los programas de mediación educativa tienen en la mejora del crecimiento integral de los alumnos y de la mejora del clima de convivencia escolar.

\section{La mediación escolar está siendo investigada por provocadora}

Investigadoras como Iriarte e Ibarrola nos constatan, en el artículo que firman en este número especial de mediación, la evidencia empírica de un número amplio de investigaciones sobre mediación educativa que han medido que sí se produce capacitación socioafectiva de alumnos y profesores a través de la mediación y de la resolución de conflictos.

La mediación educativa, por lo tanto, se caracteriza por provocar efectos educativos en los participantes, tanto en alumnos como en el resto de la comunidad educativa, y fuera del ámbito educativo despliega también sus efectos, tal y como expresa Bush al afirmar que "Procesos como la mediación pueden tener efectos transformadores muy valiosos para las partes y para la sociedad en general, pueden provocar cambios sociales".

Se descubre que la percepción de desarrollo de competencias sociocogni- 
tivas, emocionales y morales en los alumnos formados como mediadores escolares es destacable, que los alumnos con menos capacidades y habilidades socioafectivas son los que más se benefician de la formación como mediadores, que los alumnos aumentan su autoconfianza al ser mediadores, que aprenden herramientas útiles en la búsqueda de trabajo y que se favorece el ejercicio de una ciudadanía prosocial y proactiva. Se concluye la gran capacidad de programas de mediación educativa como el programa e-AMEDIAR para apoyar la labor del cumplimiento de las competencias claves de la LOE para la ESO y para lograr multiplicar los efectos beneficiosos de esta metodología de construcción de la paz.

La mediación es una herramienta en disposición de favorecer el crecimiento socioafectivo de los alumnos que se formen como mediadores con efectos tanto a corto plazo durante la etapa escolar, como a medio y a largo plazo en su vida como jóvenes ciudadanos.

El crecimiento socioafectivo se produce en el momento en el que los alumnos formados como mediadores con programas de mediación escolar o de alumnos ayudantes como el programa e-AMEDIAR han desarrollado distintas

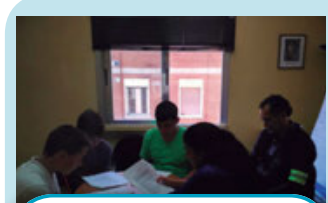

OBJETIVOS ESO

Formación en

habilidades sociales

básicas de convivencia

en aula
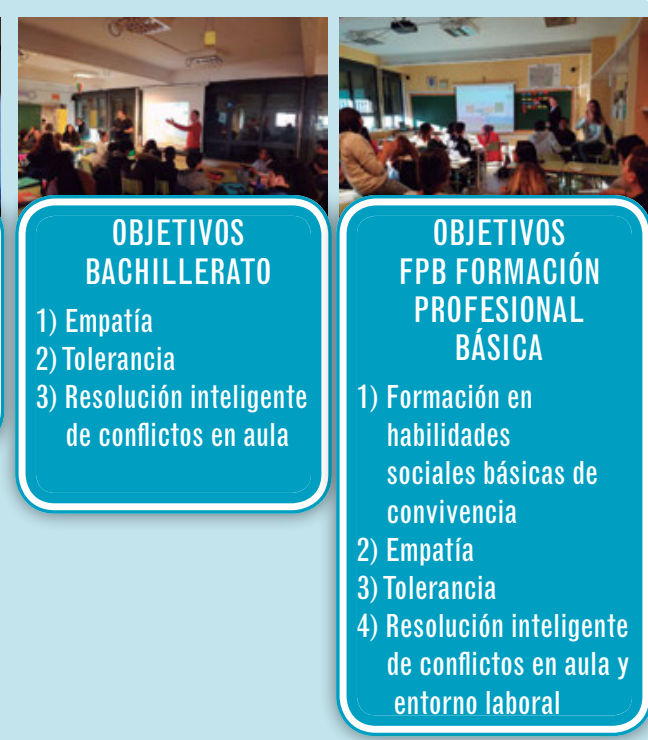

competencias sociocognitivas, emocionales y morales.

Por esta razón podemos recomendar la implantación de más programas de mediación educativa en los planes de convivencia de los centros escolares para favorecer la mejora del clima en el aula como manera eficaz de gestionar los conflictos de convivencia desde una óptica de la responsabilidad y no punitiva, que permita prevenir el acoso escolar y el bullying.

También será útil la mediación para ayudar al sistema educativo a que los

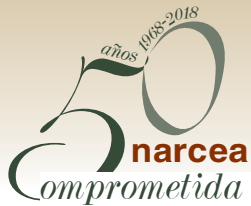

con la Eacación

\section{iQueremos} hacerte un regalo!

Entra en narceaediciones.info, introduce el código PYM0218, y descárgate gratis unas páginas de uno de nuestros libros...

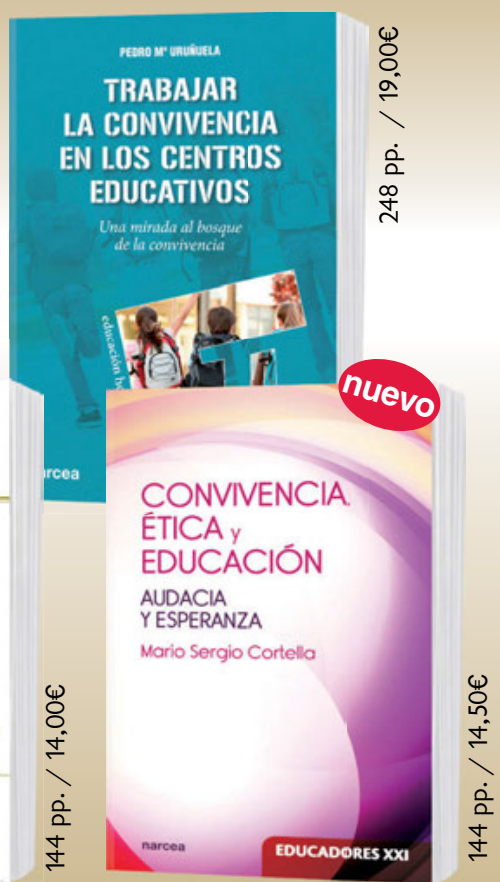




\section{ACTIVIDADES DE AULR}

\section{FICHAS PARA REALIZAR EL OBSERVATORIO DE LA CONVIVENCIA CON LOS ALUMNOS}

El profesor creará un observatorio de la convivencia durante el curso escolar en la clase para mejorar las competencias sociocognitivas de los alumnos. Dividirá la clase en 3 grupos de alumnos, cada uno deberá integrar uno de los 3 equipos: búhos, delfines 0 camaleones y realizar las funciones correspondientes explicadas en la ilustración. Durante un trimestre recogerán lo observado y lo irán compartiendo en una tutoría mensual. Cada trimestre se cambia de equipo para al cabo del curso escolar haber aprendido a ser observadores desde las 3 áreas fundamentales para ser un buen facilitador de RIC (resolución inteligente de conflictos).

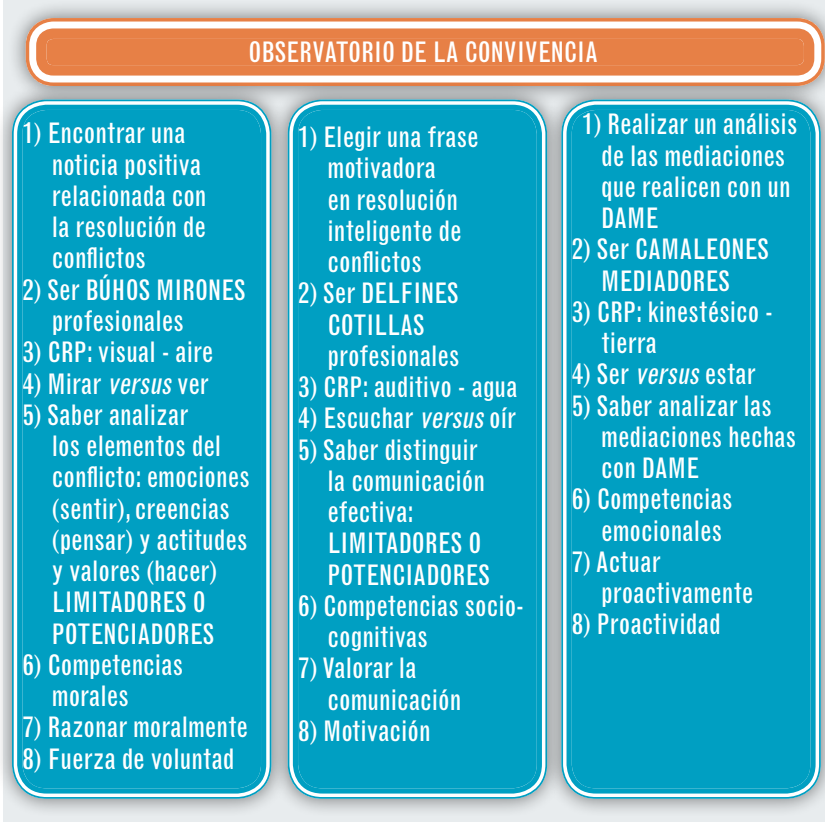

EL DELFÍN COTILLA.TE REGALO LO QUE OÍ DE CÓMO MANEJASTE LA COMUNICACIÓN

NOMBRE MEDIADOR/A:

\begin{tabular}{|l|l|}
\hline ELEMENTO A SUPERVISAR & OBSERVACIONES \\
\hline Alivia la tensión y crea confianza & \\
\hline $\begin{array}{l}\text { Usa parafraseo, reformulación, } \\
\text { chequeo }\end{array}$ \\
\hline $\begin{array}{l}\text { Distingue el lenguaje no verbal (gestos, } \\
\text { miradas, tono voz, postura cuerpo) }\end{array}$ \\
\hline $\begin{array}{l}\text { Para los insultos, amenazas, faltas de } \\
\text { respeto }\end{array}$ \\
\hline Usa buenas preguntas \\
\hline Mejora la comunicación entre ellos \\
\hline $\begin{array}{l}\text { Atrapamariposas (caza todo lo positivo } \\
\text { entre ellos) }\end{array}$ \\
\hline Otros aspectos \\
\hline
\end{tabular}

EL BÚHO MIRÓN. TE REGALO LO OUE VI DE CÓMO MANEJASTE EL CONFLICTO NOMBRE MEDIADOR/A

\begin{tabular}{|l|l|}
\hline ELEMENTO A SUPERVISAR & OBSERVACIONES \\
\hline Distingue las posiciones & \\
\hline Distingue los intereses & \\
\hline Distingue las necesidades \\
\hline Distingue las emociones \\
\hline Distingue los valores \\
\hline Obtiene toda la información necesaria \\
\hline Explora las alternativas \\
\hline Llega a acuerdos \\
\hline Habla sobre su relación, amistad \\
\hline
\end{tabular}

\section{ELEMENTO A SUPERVISAR}

OBSERVACIONES

Sigue todos los pasos de la introducción: presentarse, explicar la mediación, rol mediador, reglas mediación

Sigue las fases de resolución del conflicto: CUÉNTAME (les deja expresarse, resume, empatiza)

Sigue las fases de resolución del conflicto: ACLARÉMONOS (búsqueda de información, descubre los PINS)

Sigue las fases de resolución del conflicto: NEGOCIACIÓN (lluvia de ideas creativa, selecciona la idónea, dame un DAME)

Sigue las fases de resolución del conflicto: ACUERDO (hay TRUCO, ganador-ganador)

Papel mediador: imparcial y neutral, control del proceso, poner límites

Trabajó bien en comediación (coordinados, reparto de tareas, apoyándose, unidos, sinergia) 
alumnos alcancen más fácilmente el desarrollo de las ocho competencias claves mínimas del currículo de cada etapa educativa y a su vez favorecerá que los alumnos salgan con más herramientas para afrontar retos a medio plazo como la autoconfianza y seguridad en sí mismos que puedan aplicar en distintos ámbitos de su vida, como en la búsqueda de trabajo.

Es decir, que a través del clima escolar no solo se logra resolver los conflictos, sino que los aprendizajes se producirán en primer lugar, durante la convivencia producida en la formación como mediadores, en la que son capacitados socioemocionalmente y posteriormente, en el ejercicio de la mediación con casos reales tras la creación de servicios de mediación. Todos estos aprendizajes mejoran la convivencia y evitan situaciones de bullying, como expresan distintos autores.

La formación que se realiza con los mediadores pretende permitirles adquirir competencias para la vida, actitudes y habilidades que los ayuden a desenvolverse en sus entornos y a tomar decisiones con más fundamento, aumentando su capacidad para ser sensibles a las necesidades de los demás, ayudándoles a ser líderes naturales de sus compañeros.

\section{La mediación escolar desarrolla competencias emocionales, sociocognitivas y morales}

A corto plazo, los alumnos mediadores aprenden a relacionarse mejor con las personas que les rodean a partir de un mayor autoconocimiento, porque como mediadores se ponen al servicio de sus compañeros para ayudarles a resolver conflictos y a mejorar la comunicación evitando situaciones de acoso escolar; son mejor considerados por el resto de compañeros porque pasan a tener unas funciones y responsabilidades bien valoradas en su rol de mediadores. Por lo tanto, es aconsejable el desarrollo de programas de mediación educativa como e-AMEDIAR para favorecer la inclusión educativa de estos alumnos en sus clases y en el centro educativo de-

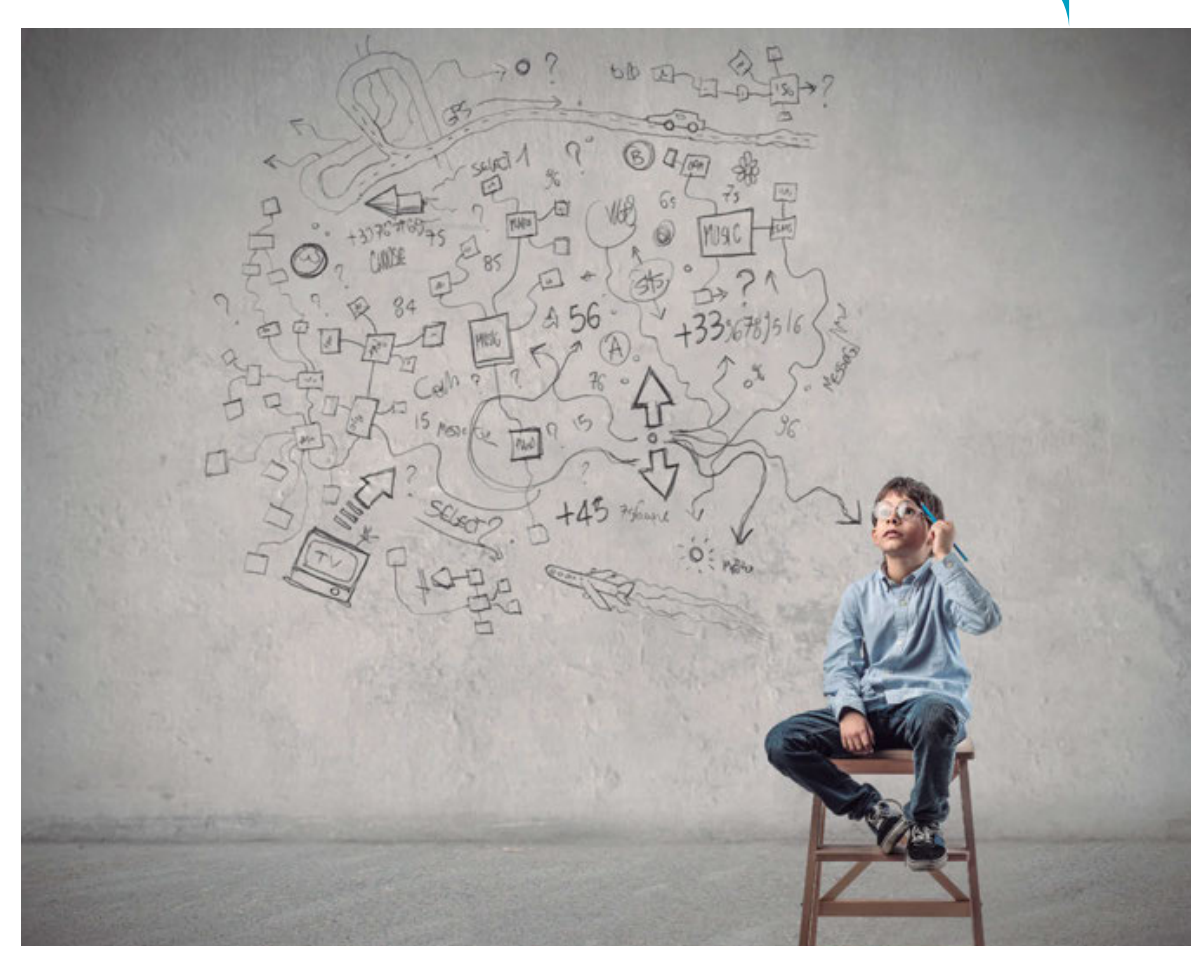

sarrollando competencias sociocognitivas a través de un mayor reconocimiento ante los demás.

A medio plazo, los ya exalumnos mediadores aprenden a sacar lo mejor de sí mismos en las entrevistas de trabajo, a partir de una mayor autoconfianza y autoestima, porque como mediadores aumentaron su inteligencia emocional, tratando casos reales de conflictos de sus compañeros y teniendo que ayudarlos durante las sesiones a que entendieran y controlaran sus emociones, lo cual pueden hacer como mediadores solo cuando ellos mismos han realizado durante el curso de formación un importante trabajo personal de autocontrol de sus propias emociones. Por lo tanto, podremos aconsejar la puesta en marcha de formación y de servicios de mediación en los centros escolares, para facilitar la futura inserción laboral de estos alumnos desarrollando competencias emocionales, mediante el aumento de la seguridad en sí mismos por tener inteligencia emocional que les haga más atractivos para las empresas en sus entrevistas de trabajo.

A largo plazo, los alumnos formados como mediadores con el programa e-AMEDIAR que ya son jóvenes ciudadanos, aprenden a tener una actitud prosocial en los entornos de convivencia en los que se encuentran y a involucrarse 


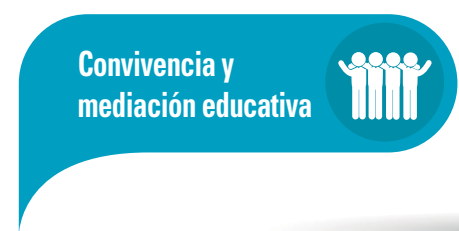

Ventajas y beneficios de la mediación escolar

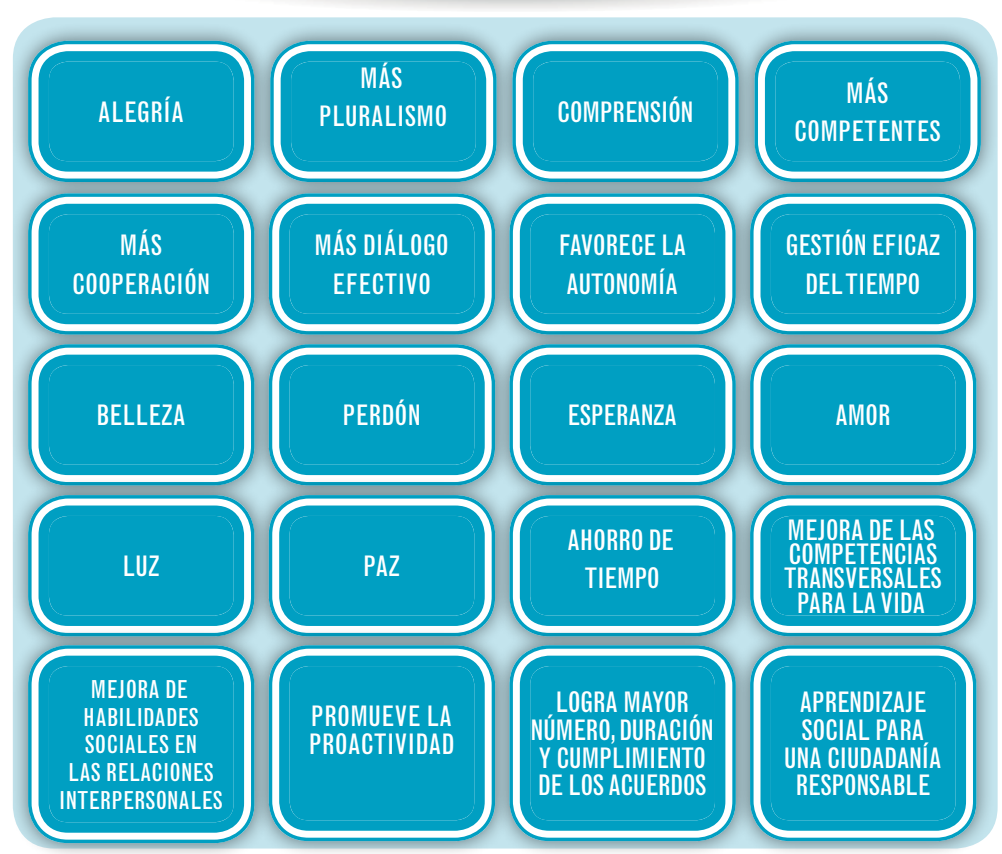

$\Delta$

Contenidos en prevención del acoso escolar en la participación ciudadana a partir de una mayor responsabilidad, porque como mediadores aprendieron la importancia de ser agentes activos y no pasivos, en la mejora de la convivencia en el centro escolar, asumiendo la responsabilidad de ser agentes de paz. Por lo tanto, podremos aconsejar la implantación de programas de mediación educativa para facilitar una futura integración social de estos alumnos desarrollando competencias morales a través del ejercicio de una ciudadanía

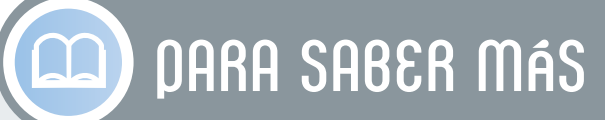

McAuslan, F. (2015). Performance-based Conflict Resolution Training for Children. Journal of Mediation \& Applied Conflict Analysis, 2(2). Disponible en: http:// eprints. maynoothuniversity. ie/6255/1/ Fiona_MCL_article_FINAL_12.7.pdf

Mediación escolar Padre Piquer programa e-AMEDIAR. (n.d.). Recuperado de: https://www.facebook.com/mediadorespadrepiquer/?ref=bookmarks

Miranzo de Mateo, S. (21 de marzo de 2014). Presentation of School peer mediation program e-AMEDIAR in Padre Piquer Madrid [Archivo de vídeo]. Recuperado de https://youtu.be/COz1L9uNgFc proactiva de estos alumnos en el entorno en el que vivan.

\section{Ventajas de la mediación escolar \\ Las raíces filosóficas de la mediación} educativa parten de la misma concepción que las de la mediación general, una mirada positiva basada en la cultura de la no-violencia, de la resolución alternativa de conflictos, de la implantación de los derechos humanos y de los derechos de la infancia, aplicada a través de las materias transversales del currículo escolar.

Las grandes ventajas que aporta la mediación escolar deben hacer reflexionar a los directores de centros escolares sobre por qué aún no hay un servicio de mediadores escolares en cada colegio y sobre cómo lograr tener uno cuanto antes para poder beneficiarse de la satisfacción de necesidades que esta intervención profesional logra.

\section{Conclusiones}

La creación de programas de mediación escolar, de alumnos ayudantes y de cibermentores es una realidad en expansión, su implantación no requiere de grandes esfuerzos económicos sino de grandes voluntades y propósitos.

Como dice el director de Padre Piquer, Ángel Serrano, siempre que presenta el Servicio de Mediación del centro escolar a los que visitan el centro: "nuestro ideal a conseguir es que de 1.200 alumnos tengamos 1.200 mediadores" •

\section{(-) \\ Mediación escolar; mediación educativa; e-AMEDIAR; solución de conflictos; desarrollo de competencias; convivencia; prevención acoso escolar; bullying.}

Este artículo fue solicitado por PADRES Y MAESTROS en septiembre de 2017, revisado y aceptado en diciembre de 2017. 